\title{
ПОЛИТИЧЕСКИЕ И ПРАВОВЫЕ АСПЕКТЫ ПАРАДИПЛОМАТИИ КАНАДСКИХ ПРОВИНЦИЙ И СУБЪЕКТОВ РОССИЙСКОЙ ФЕДЕРАЦИИ: ОБЩЕЕ И ОСОБЕННОЕ
}

\section{POLITICAL AND LEGAL ASPECTS OF PARADIPLOMACY: COMPARING CANADIAN PROVINCES AND SUBJECTS OF RUSSIAN FEDERATION}

\author{
Ю.Г. Акимов \\ Y.G. Akimov \\ Санкт-Петербургский государственный университет, \\ Россия, 199034, г. Санкт-Петербург, Университетская наб., 7/9 \\ St Petersburg State University, \\ 7/9 Universitetskaya embankment, St. Petersburg, 199034, Russia \\ E-mail: y.akimov@spbu.ru
}

\begin{abstract}
Аннотация
Статья посвящена сравнительному анализу международной деятельности (парадипломатии) субъектов Российской и Канадской федераций. Рассматриваются сходства и различия российской и канадской модели федерализма, выясняется правовой статус внешних связей субъектов, формы и методы их осуществления. Подчеркивается, что развитие федеративных отношений в Канаде идет по формуле симметрия de jure при асимметрии de facto, что, с одной стороны, позволяет избежать конфликта между субъектами и в то же время дает им возможность отстаивать свои интересы и реализовать локальные потребности, оставаясь в рамках федерации. Отмечаются те стороны канадского опыта провинциальной парадипломатии, которые могут быть полезны для регионов Российской Федерации.
\end{abstract}

\begin{abstract}
The article presents a comparative analysis of paradiplomatic activity of the subjects of the Russian Federation and Canadian provinces. Special attention is given to political and legal aspects of paradiplomacy. It shows similarities and differences between the Russian and Canadian models of federalism as well as the legal status of subjects' external relations, their forms and methods. It is emphasized that the evolution of contemporary Canadian Federalism follows the formula of de jure symmetry with de facto asymmetry. On the one hand, such combination helps to avoid conflicts between provinces and gives them opportunity to achieve their specific goals and interests while remaining respectful members of the Federation. The author shows the specificity of Quebec Identity Paradiplomacy and the role of Gérin-Lajoie doctrine in its development. The article stresses those aspects of Canadian provinces' paradiplomatic experience that could be applicable for subjects of the Russian Federation, which are currently taking an increasingly active part in the implementation of Russia's foreign policy.
\end{abstract}

Ключевые слова: парадипломатия, провинции Канады, субъекты Российской Федерации, внешняя политика, федерализм, региональная идентичность.

Keywords: Paradiplomacy, Canadian Provinces, Subjects of Russian Federation, Foreign Policy, Federalism, Sub-National Identity, Quebec.

Россия и Канада - две крупнейшие по территории федерации мира с полиэтничным и мультикультурным составом населения. Субъекты обеих из них активно развивают соб- 
ственные внешние связи различного уровня. Данное явление, получившее собирательное название парадипломатия, в конце XX - начале XXI в. стало заметным фактором международных отношений. В настоящей статье мы остановимся на политических и правовых аспектах парадипломатии канадских провинций и субъектов Российской Федерации (а также на тех внутренних факторах, которые на нее влияют) и постараемся выявить их сходства и различия.

Говоря о парадипломатии субъектов той или иной федерации, прежде всего следует обратить внимание на особенности ее федеративного устройства, а также на специфику ее политического режима и сложившихся в ней федеративных отношений. Очевидно, что канадский и российский варианты федерализма имеют ряд существенных отличий. Это связано как с историческими особенностями формирования двух федераций, так и с теми базовыми принципами, на которых они строились. Канада - договорная, централизованная парламентская федерация с монархической формой правления [Данилов, 2012, с. 55], недавно отметившая свой полуторавековой юбилей. Современное Российское государство сформировалось в начале 1990-х гг. как конституционно-договорная федерация (хотя с этим согласны не все исследователи [Мелкумов, 2010, с. 60]); в начале XXI в. характер российского федерализма стал меняться [Захаров, 2012].

И Канада, и Россия являются асимметричными федерациями. Однако характер данной асимметрии представляется различным. В Канаде она носит скрытый характер и связана главным образом с некоторыми положениями Конституционного акта 1867 г., составляющего основу ее конституции. В частности, там закреплено неравное представительство провинций в верхней палате парламента (Сенате), наличие разных типов провинциальных легислатур, а также некоторые правовые особенности провинции Квебек [Данилов, 2012, с. 56-59].

В дальнейшем развитие канадского федерализма шло по пути, который, на наш взгляд, можно охарактеризовать формулой: симметрия de jure при асимметрии de facto. С одной стороны, сохранялось и подчеркивалось равенство конституционно-правового статуса субъектов, с другой - допускалась, признавалась и развивалась фактическая асимметрия.

Прежде всего это было связано с провинцией Квебек, которая с момента образования федерации de facto занимала в ней особое положение. Безусловно, главной причиной этого являлось то обстоятельство, что основную массу населения Квебека составляли франкофоны. До начала 1960-х гг. применительно к ним чаще использовался этноним франко-канадцы (Canadiens français / French Canadians), а затем распространение получил термин квебекцы (Québécois) - причем как во французском, так и в английском языке (в русскоязычной научной литературе иногда встречается вариант франко-квебекцы). В настоящее время франко-канадцы / франко-квебекцы составляют более 80 \% населения Квебека. Это обстоятельство отличает его от всех остальных провинций, где большинство населения составляют англоязычные канадцы: англо-канадцы (English Canadiqns) и представители других этнических групп. Территория Квебека представляет собой «историческое ядро» Французской Канады, возникшей в результате французской колонизации долины реки Св. Лаврентия и прилегающих областей Североамериканского континента в XVII - середине XVIII вв., и затем завоеванной англичанами в ходе Семилетней войны (1756-1763). С 1960-х гг. (в период так называемой Тихой революции) Квебек и его провинциальные институты стали рассматриваться франко-канадцами как главный политический и экономический инструмент выражения, защиты и продвижения их коллективных прав и интересов [Balthazar, 1986].

Согласно распространенному в Канаде выражению, Квебек всегда был «провинцией не как все» («pas comme les autres»). C 1960-х гг. его лидеры стали позиционировать провинцию как «федерированное государство»; в 1970-90-е гг. там имело место достаточно мощное суверенистское движение; в 1982 г. Квебек отказался признать конституционную реформу, что породило конституционный кризис, продолжающийся по сей день. Од- 
нако чрезвычайно важно подчеркнуть, что, несмотря на все вышеперечисленное, конституционно-правовой статус провинции не менялся! Во второй половине 1980-х - начале 1990-х гг. правительством М.Б. Малруни дважды предпринимались попытки преодолеть конституционный кризис за счет законодательного закрепления «особого статуса» Квебека, что означало бы переход от скрытой асимметрии канадского федерализма к открытой. Обе эти попытки (Мич-Лейкское и Шарлоттаунское соглашения 1987 и 1992 гг. соответственно) провалились, в первую очередь из-за оппозиции других провинций, не желавших нарушать внешнюю симметрию федерации и предоставлять одному из субъектов особые права. В поисках выхода из сложившейся ситуации канадское федеральное правительство пошло по пути расширения прав субъектов (формально - всех), подразумевая, что этим воспользуется только Квебек, однако внешняя симметрия федерации не будет нарушена.

В отличие от Канады, в России асимметрия федерализма не является скрытой. Конституция Российской Федерации закрепляет за республиками бо́льшие права, чем за другими субъектами. В 1990-е асимметрию еще больше усиливала практика заключения двусторонних договоров «о разграничении предметов ведения и взаимном делегировании полномочий» [Сборник, 1997] между центром и субъектами, которые часто являлись результатом межэлитного «торга» [Мартьянов, 2010]. С начала 2000-х гг. эта практика постепенно была свернута, однако не только формальная, но и неформальная асимметрия российского федерализма продолжает сохраняться [Панкевич, 2008].

В Канаде и России по-разному регламентируется конституционно-правовой статус международной деятельности субъектов федерации. В Канаде он базируется на только (и не столько) на самой конституции, сколько на решениях высших судебных инстанций (то есть на прецедентах) и их толковании. Дело в том, что в Конституционном акте 1867 г. вообще нет статей, где регламентируются вопросы реализации внешней политики и соотношения международных договоров и внутреннего права. Это связано с тем, что данный документ (первоначально он назывался Акт о Британской Северной Америке) создавался как основной закон доминиона, являющегося составной частью Британской империи, а не суверенного государства. Впоследствии, когда Канада в 1931 г. обрела внешнеполитический суверенитет, данный пробел не был устранен, хотя фактически внешняя политика сосредоточилась в руках федерального центра. В то же время уже в конце XIX - начале $\mathrm{XX}$ в. провинции начали делать первые самостоятельные шаги на международной арене, открывая в Европе свои представительства с целью развития торговли, получения займов и привлечения иммигрантов. Впрочем, масштабы этой деятельности были достаточно скромными, а лица, осуществлявшие ее, действовали скорее как коммерческие агенты и вербовщики, а не как чиновники (и тем более не как дипломаты). Соответственно, вопрос о конституционно-правовом статусе этой деятельности не поднимался.

Ситуация кардинально изменилась в 1960-е гг. Главным «виновником» изменений стал, что неудивительно, Квебек. В годы Тихой революции его международная деятельность не просто резко активизировалась, но вышла на качественно иной уровень. С одной стороны, многократно возросла интенсивность его контактов с зарубежными партнерами, расширился их спектр и география. С другой - внешние связи Квебека перестали носить чисто утилитарный характер и прибрели заметную неэкономическую составляющую. Франкоязычная провинция стала заявлять о себе как об автономном игроке / несуверенном акторе международных отношений, обладающем собственной идентичностью и интересами, отличными от общеканадских. Знаковым событием стало заключение в начале 1965 г. квебекско-французского «диагонального» соглашения о сотрудничестве в сфере образования, где одной стороной выступал субъект федерации, а другой - суверенное государство! Это актуализировало вопрос о праве провинций на осуществление внешних связей. В апреле 1965 г. тогдашний вице-премьер и министр образования Квебека Поль Жерен-Лажуа сформулировал доктрину внешней пролонгации внутренних компетенций провинций, впоследствии названную его именем [Allocution, 1965]. При этом он, с одной стороны, исходил из закрепленного в конституции разделения сфер компетенций между цен- 
тром и провинциями, а с другой - из судебного решения по Делу о трудовых конвенциях, вынесенного в 1937 г. Последнее гласило, что факт заключения «центром» международного договора, относящегося к сфере провинциальной юрисдикции, сам по себе не дает тому права вмешиваться в эту сферу [Акимов, 2016]. Доктрина Жерен-Лажуа отстаивает право провинций вести международные переговоры и заключать соглашения с иностранными партнерами по тем вопросам, которые по конституции отнесены к провинциальной или конкурирующей юрисдикции. Это, прежде всего, образование, природные ресурсы, энергетика, пути сообщения, иммиграция. Данная доктрина стала основой международной деятельности Квебека; ее положения стали использовать и другие провинции.

Со своей стороны федеральное правительство, официально не согласившись со всеми положениями доктрины Жерен-Лажуа, в итоге пошло на уступки провинциям, стремившимся действовать на международной арене в сфере своей юрисдикции. В конце 1984 г. министр иностранных дел Канады Джо Кларк направил провинциальным премьерам письмо, где говорилось о признании «законных интересов [провинций] в сфере международных отношений» и в то же время подчеркивалась необходимость «избегать размывания имиджа Канады за границей» [Blanchette, 1994, p. 139].

Конечно, между двумя уровнями власти случались и конфликты по поводу международной деятельности. Опять-таки чаще всего эти конфликты были связаны с Квебеком особенно в периоды нахождения у власти Квебекской партии (1976-1985, 1994-2003, 2012-2014), выступавшей за суверенитет провинции и дважды проводившей референдумы по данному вопросу (в 1980 и 1995 гг.). Очевидно, что в эти критические моменты внешние связи провинции выходили за рамки парадипломатии субъекта федерации, превращаясь в протодипломатию непризнанной нации [Histoire, 2006, p. 194-196], что, естественно, вызывало противодействие федерального центра, стоявшего на страже территориальной целостности и единства страны. В то же время с начала 2000-х гг. эти конфликты не просто сошли на нет, но постепенно сменились конструктивным и взаимовыгодным федерально-провинциальным сотрудничеством [Акимов, 2011].

В России конституция относит внешнюю политику к ведению федерального центра [Конституция, 1993, ст. 71 к] и возлагает на него ответственность за исполнение международных договоров, которым дается приоритет над внутренним законодательством [Конституция, 1993, ст. 15.4]. В то же время она закрепляет за субъектами федерации право на развитие «международных и внешнеэкономических связей», относя их координацию к совместному ведению федерального центра и субъектов [Конституция, 1993, ст. 72.о].

Выход на международную арену субъектов Российской Федерации начался в период «парада суверенитетов» рубежа 1980-1990-х гг. На первых порах данный процесс носил хаотичный и неорганизованный характер, что было связано с общей кризисной ситуацией в стране, испытывавшей разнообразные трудности переходного периода. Внешние связи рассматривались руководством многих субъектов в первую очередь как одно из средств улучшения тяжелой социально-экономической ситуации. Кстати, первоначально именно с этой целью республиками стали использоваться элементы «идентификационной парадипломатии». Так, Карелия с 1992 г. получала значительные объемы гуманитарной помощь от «родственной» Финляндии [Цумарова, 2013]. В этой ситуации между центром и субъектами возникали конфликты (например, по поводу соглашения Калининградской области с Литвой, аннулированного в 1995 г.). Однако уже к середине 1990-х гг. ситуация стала меняться. С одной стороны, начала формироваться законодательная база функционирования механизмов координации внешних связей субъектов (принятие Федерального закона «О международных договорах Российской Федерации» (1995), издание Указа Президента «О координирующей роди Министерства иностранных дел Российской Федерации» (1996), принятие Федерального закона «О координации международных и внешнеэкономических связей субъектов Российской Федерации» (1999) и др.). С другой, сами субъекты приобрели определенный опыт и стали воздерживаться от необдуманных решений и рискованных шагов. 
Уже в самом слове «парадипломатия» содержится прямой намек на то, что она имеет общие черты с «традиционной» дипломатией, которую осуществляют суверенные государства. Действительно, по форме международная деятельность многих субнациональных акторов (и прежде всего субъектов федераций) нередко напоминает национальную внешнюю политику. У субнационального актора может быть специальное ведомство, занимающееся внешними связями и собственные представительства за границей; он может заключать двусторонние соглашения, участвовать в деятельности международных организаций, принимать программы международной деятельности и т. п. Однако очевидно, что это лишь внешнее сходство, за которым стоит принципиальное различие, связанное с наличием/отсутствием суверенитета, полной/частичной международной правосубъектностью и всеми вытекающими отсюда последствиями.

Канадские провинции используют различные формы осуществления международных связей. Так, у Квебека международная деятельность по структуре и по оформлению напоминает организацию внешней политики суверенного государства. Безусловно, это связано с главной особенностью квебекской парадипломатии - наличием в ней «идентификационной» составляющей, являющейся элементом национального строительства «квебекской нации» [Paquin, 2005].

В настоящее время Квебек обладает разветвленной сетью провинциальных представительств в государствах Европы, Азии, Африки, Северной и Южной Америки. Он также представлен в международной организации франкофонии и ЮНЕСКО. Провинция имеет собственное министерство международных отношений и франкофонии, отвечающее за внешние связи. Квебекское правительство регулярно выпускает белые книги по международным отношениям и принимает стратегические планы действий на международной арене [Акимов, 2017]. В международной деятельности Квебека отчетливо видны два основных направления: экономическое (нацеленное на США) и культурнолингвистическое (связи с Францией и франкоязычными странами и структурами [Акимов и др. 2007]).

Большинство провинций «Остальной» (или Английской) Канады начали развивать свои внешние связи с середины - второй половины 1970-х гг. В отличие от Квебека их контакты с зарубежными партнерами были продиктованы почти исключительно материальными (экспорт, импорт, инвестиции, туризм) и функциональными (экология, транспортная логистика) интересами. Первоначально провинции Английской Канады также пошли по пути создания сетей собственных зарубежных представительств. К началу 1990-х гг. практически все они обладали агентствами или офисами за границей, в частности, у провинции Онтарио их насчитывалось 18, у Британской Колумбии - 9 [Blanchette, 1994, p. 147-148]. К середине в 1990-х гг. в условиях экономического спада многие провинции либо вообще отказались от представительств, либо существенно урезали их численность и бюджет (так, Онтарио в 1993 г. закрыло все свои агентства).

В настоящее время провинции используют различные формы организации международной деятельности. У некоторых сохраняется сеть постоянных представительств. Например, у стремительно развивающейся Альберты имеется 12 зарубежных офисов, причем 9 из них находятся в Южной и Юго-Восточной Азии. Онтарио в начале XXI в. активно развивает практику провинциальных торговых миссий - масштабных делегаций, объединяющих представителей бизнеса и администрации этой крупнейшей провинции. Еще одной формой осуществления международного сотрудничества является участие в организациях, объединяющих губернаторов штатов США и премьеров провинций Канады, относящихся к определенному региону (Совет губернаторов и премьеров региона Великих озер и реки Св. Лаврентия и т. п.) [McHugh, 2015]. Практически в каждой провинции приняты собственные программы/стратегии развития международной деятельности. Важным инструментом продвижения провинциальных интересов на международной арене является цифровая дипломатия (в том числе аккаунты в социальных сетях) [Минкова, 2016]. 
В Российской Федерации с начала 1990-х гг. субъекты шли по «традиционному» пути - создание постоянных представительств, учреждение департаментов/комитетов по внешним связям и т. п. Безусловно, на определенном этапе эта практика принесла свои плоды: был накоплен опыт (как позитивный, так и негативный), налажены контакты, определены перспективные и заинтересованные партнеры. Однако представляется, что в настоящее время субъекты могут пойти по пути диверсификации форм осуществления внешних связей, используя в том числе опыт канадских провинций.

Еще одной характерной чертой международной деятельности субъектов Российской Федерации является их более тесное вовлечение в реализацию общенациональных задач, стоящих перед внешней политикой нашей страны. Наиболее ярко данная тенденция стала проявляться во второй половине 2010-х гг. В настоящее время «внешние связи регионов, согласованные с общенациональными интересами, становятся важным фактором успешного развития государства в современном мире и повышения общей конкурентоспособности территорий в его составе» [Гиматдинов и др. 2019. с. 13].

Канадские провинции обладают большим и разносторонним опытом выстраивания международных контактов с партнерами различного уровня. Представляется, что российские регионы могут использовать некоторые формы и методы международной деятельности, успешно применяемые субъектами Канадской федерации. В то же время в условиях резкого охлаждения двусторонних отношений Москвы и Оттавы, произошедшего в последние годы, региональный уровень может стать своего рода альтернативным каналом взаимовыгодного сотрудничества двух стран. К настоящему времени субъектами Российской Федерации и канадскими провинциями накоплен значительный опыт развития двусторонних контактов. На региональном уровне есть возможность обойти «острые углы», найти узко-профильные точки соприкосновения, и, что немаловажно, избежать воздействия тех сил в Канаде, которые в настоящее время не заинтересованы в нормализации российско-канадских отношений.

\section{Список литературы}

1. Акимов Ю.Г. 2016. Канадский федерализм и конституционно-правовой статус квебекской парадипломатии. Управленческое консультирование, 11: 18-26.

2. Акимов Ю.Г. 2011. Квебекская парадипломатия и позиция федерального правительства Канады: от конфликта к компромиссу. Вестник Санкт-Петербургского университета. Сер. 6, 4: 48-56.

3. Акимов Ю.Г. 2017. Организация международной деятельности субъекта федерации (на примере канадской провинции Квебек). Управленческое консультирование, 12 (108): 22-32.

4. Акимов Ю.Г., Костюк Р.В., Чернов И.В. 2007. Франция в мировом порядке начала XXI в. СПб., Издательство Санкт-Петербургского университета, 198.

5. Гиматдинов Р., Насыров И., Садыкова Э. 2019. Участие регионов в реализации внешней политике Российской Федерации. Международная жизнь. Август: 12-25.

6. Данилов С.Ю. 2012. Эволюция канадского федерализма. М., Издательский дом ВШЭ: 303.

7. Захаров А.А. 2012. «Спящий институт». Федерализм в современной России и мире. М., НЛО: 144.

8. Конституция Российской Федерации. 1993. Официальный сайт. URL: http://www.constitution.ru/index.htm (дата обращения 28 февраля 2019).

9. Мартьянов В.С. 2010. Федерализм: политическое устройство или пакт элит? ПОЛИС. Политические исследования. 1: 173-184.

10. Мелкумов А.А. 2010. Российская и канадская модели федерации: сравнительный анализ. М., Логос: 392.

11. Минкова К.В. 2016. Цифровая дипломатия как новое направление публичной дипломатии. В кн.: Дипломатия на Востоке и Западе: взгляд из Сибири: всероссийская научная конференция (Иркутск, 13 мая 2016 г.): материалы. Иркутск, Издательство Иркутского государственного университета: 19-26.

12. Панкевич Н.В. 2008. Модели федеративного устройства: закономерности политической трансформации. Екатеринбург, УрО РАН: 194. 
13. Сборник договоров и соглашений между органами государственной власти Российской Федерации и органами государственной власти субъектов Российской Федерации. 1997. М., Издание Государственной Думы; Известия: 776.

14. Цумарова Е.Ю. 2013. Европейский дискурс в политике идентичности Республики Карелия Studia Humanitatis Borealis. 1: 42-52.

15. Allocution du ministre de l'Éducation, M. Paul Gérin-Lajoie. Québec, hôte officiel du Corps consulaire de Montréal. Montréal, le 12 avril 1965. URL: http://www.mrif.gouv.qc.ca/fr/Ministere/Historique/Doctrine-Paul-Gerin-Lajoie/allocutions-discoursofficiels/pgl1965/ (дата обращения 28 февраля 2018).

16. Balthazar L. 1986. Bilan du nationalisme au Québec. Montréal, Les Éditions de L’Hexagone: 217.

17. Blanchette A. 1994. Canadian Foreign Policy, 1977-1992: Selected Speeches and Documents. Montreal, McGill-Queen's University Press: 197.

18. Histoire des relations internationales du Québec. 2006. Montréal, VLB éditeur: 357.

19. McHugh J.T. 2015. Paradiplomacy, protodiplomacy ant the foreign aspirations of Quebec and Other Canadian Provinces. Canadian Foreign Policy Journal. 21, 3: 238-256.

20. Paquin S. 2005. La paradiplomatie identitaire. Le Québec, la Flandre et la Catalogne en relations internationales. Politique et Sociétés. 23, 3: 176-194.

21. Soldatos P. 1990. An Explanatory Framework for the Study of Federated States as ForeignPolicy Actors. In: Federalism and International Relations: The Role of Subnational Units. Oxford, Oxford University Press: 34-53.

\section{References}

1. Akimov Yu.G. 2016. Kanadskiy federalizm i konstitutsionno-pravovoy status kvebekskoy paradiplomatii [Canadian Federalism and Constitutional-Legal Status of Quebec Paradiplomacy]. Upravlencheskoe konsul'tiro-vanie, 11: 18-26.

2. Akimov Yu.G. 2011. Kvebekskaya paradiplomatiya i pozitsiya federal'nogo pravitel'stva Kanady: ot konflikta k kompromissu [Quebec paradiplomacy and Canadian federal government: from conflict to compromise]. Vestnik Sankt-Peterburgskogo universiteta. $6^{\text {th }}$ Series, 4: 48-56.

3. Akimov Yu.G. 2017. Organizatsiya mezhdunarodnoy deyatel'nosti sub"ekta federatsii (na primere kanadskoy provintsii Kvebek) [Organization of the International Activity of the Territorial Subject of the Federation (on the Example of the Canadian Province of Quebec)]. Upravlencheskoe konsul'tirovanie, 12 (108): 22-32.

4. Akimov Yu.G., Kostyuk R.V., Chernov I.V. 2007. Frantsiya v mirovom poryadke nachala XXI v. [France in World Order at the beginning of the $21^{\text {st }}$ century] Saint-Petersburg, Saint-Petersburg University Press, 198.

5. Gimatdinov R., Nasyrov I., Sadykova E. 2019. Uchastie regionov v realizatsii vneshney politike Rossiyskoy Federatsii [Participation of Regions in the Implementation of the Foreign Policy of Russian Federation]. Mezhdunarodnaya zhizn'. Avgust: 12-25.

6. Danilov S.Yu. 2012. Evolyutsiya kanadskogo federalizma [Evolution of Canadian Federalism]. Moscow, HSE Publishing House: 303.

7. Zakharov A.A. 2012. «Spyashchiy institut». Federalizm v sovremennoy Rossii i mire [«Sleeping Institution»: Federalism in contemporary Russia and in the World]. Moscow, NLO: 144.

8. Konstitutsiya Rossiyskoy Federatsii. 1993. Ofitsial'nyy sayt [Constitution of the Russian Federation. 1993. Official website]. URL: http://www.constitution.ru/index.htm (accessed February, 28, 2018)

9. Mart'yanov V.S. 2010. Federalizm: politicheskoe ustroystvo ili pakt elit? [Federalism: political structure or a pact between elites?]. POLIS. Politicheskie issledovaniya. 1: 173-184.

10. Melkumov A.A. 2010. Rossiyskaya i kanadskaya modeli federatsii: sravnitel'nyy analiz [Russian and Canadian Models of Federalism: Comparative Analyses]. Moscow, Logos: 392.

11. Minkova K.V. Tsifrovaya diplomatiya kak novoe napravlenie publichnoy diplomatii [Digital Diplomacy as a new type of Public Diplomacy]. In: Diplomatiya na Vostoke i Zapade: vzglyad iz Sibiri. Irkutsk, Irkutsk State University Press: 19-26.

12. Pankevich N.V. 2008. Modeli federativnogo ustroystva: zakono-mernosti politicheskoy transformatsii [Models of Federalism: Patterns of Political Transformation]. Ekaterinburg, UrO RAN: 194. 
13. Sbornik dogovorov i soglasheniy mezhdu organami gosudarstvennoy vlasti Rossiyskoy Federacii i organami gosudarstvennoy vlasti sub'ektov Rossiyskoy Federacii [A Collection of Treaties and agreements between the state authorities of the Russian Federation and the state authorities of the subjects of the Russian Federation]. 1997. M., Izdanie Gosudarstvennoy Dumy; Izvestiya: 776.

14. Tsumarova E.Yu. 2013. Evropeyskiy diskurs v politike identichnosti Respubliki Kareliya [European discourse in the identity politics of the Republic of Karelia]. Studia Humanitatis Borealis. 1: 42-52.

15. Allocution du ministre de l'Éducation, M. Paul Gérin-Lajoie. Québec, hôte officiel du Corps consulaire de Montréal. Montréal, le 12 avril 1965. URL: http://www.mrif.gouv.qc.ca/fr/Ministere/Historique/Doctrine-Paul-Gerin-Lajoie/allocutions-discoursofficiels/pgl1965/ (дата обращения 28 февраля 2018)

16. Balthazar L. 1986. Bilan du nationalisme au Québec. Montréal, Les Éditions de L’Hexagone: 217.

17. Blanchette A. 1994. Canadian Foreign Policy, 1977-1992: Selected Speeches and Documents. Montreal, McGill-Queen's University Press: 197.

18. Histoire des relations internationales du Québec. 2006. Montréal, VLB éditeur: 357.

19. McHugh J.T. 2015. Paradiplomacy, protodiplomacy ant the foreign aspirations of Quebec and Other Canadian Provinces. Canadian Foreign Policy Journal. 21, 3: 238-256.

20. Paquin S. 2005. La paradiplomatie identitaire. Le Québec, la Flandre et la Catalogne en relations internationales. Politique et Sociétés. 23, 3: 176-194.

21. Soldatos P. 1990. An Explanatory Framework for the Study of Federated States as ForeignPolicy Actors. In: Federalism and International Relations: The Role of Subnational Units. Oxford, Oxford University Press: $34-53$.

\section{Ссылка для цитирования статьи Link for article citation}

Акимов Ю.Г. 2020. Политические и правовые аспекты парадипломатии канадских провинций и субъектов Российской Федерации: общее и особенное. Via in tempore. История. Политология, 47 (2): 397-404. DOI 10.18413/2687-0967-2020-47-2-397-404.

Akimov Y.G. 2020. Political and legal aspects of paradiplomacy: comparing canadian provinces and subjects of russian federation. Via in tempore. History and political science, 47 (2): 397-404 (in Russian). DOI 10.18413/2687-0967-2020-47-2-397-404. 